\title{
Computer-aided design system for control moment gyroscope
}

\author{
Tamara Kostyuchenko*, and Nelya Indygasheva \\ Tomsk Polytechnic University, 634050 Tomsk, Russia
}

\begin{abstract}
Control moment gyroscope or two-axis balking gyroscope is used in spacecraft orientation systems. The control moment gyroscope is a complex electromechanical system with different parameters which connect by means of specific instant and inverse dependences. This fact could complicate the design process as of getting the optimal parameters the search of construction variations becomes harder. To simplify the control moment gyroscope designing process and increase its efficiency the computer-aided design system could be as highly useful. The computer-aided design system which is used in the present research and described in the article consists of five main subsystems. They cover the main stages of control moment gyroscope designing.
\end{abstract}

\section{Introduction}

Modern spacecraft orientation and stabilization systems are based on using the final controlling elements [1]. These elements create the command torque in the stabilization and programmed turns regimes of spacecraft in relation to directional reference. Control moment gyroscope (CMG) is one of such elements. The CMG is a two-axis balking gyroscope which is used for the precision stabilization and orientation of spacecraft. The CMG maintains the required orientation during the flight and prevents the random rotation of spacecraft.

Computer-aided design system (CAD-system) is an automated computer system which provides the advanced facilities for designing. CAD-system is an organizational and technical system for realization the automation designing process and consists of a complex technical, software and other means [2-8].

CAD-system in application of designing the CMG allows automating the designing process. It makes possible to decrease the designing time and improve the final quality of the device.

\section{Methods}

Currently, there is a large number of CAD-systems which allow creating the 3D models of construction details.

\footnotetext{
* Corresponding author: $\underline{\operatorname{tg} @ \operatorname{tpu} . r u}$
} 
These 3D models are the basis as for the design documentation and production as for the further simulation in order to test the device characteristics.

The russian software complex T-Flex is one of such type of CAD-systems. It contains the wide range of necessary tools and means for designing. The main advantage of the TFlex system is the parametric capabilities which allows optimizing the developing construction during the designing process.

The block diagram which is shown in the Figure 1 presents the structure of the CMG designing process in T-Flex system. The whole designing process is distributed between five subsystems which are deal with the certain design calculations. Thus, the results from each subsystem will be accumulated to perform the final parameters of the developing CMG. These subsystems are the following:

- geometric modeling subsystem;

- subsystem of operational characteristics calculation;

- subsystem of strength characteristics calculation;

- design documentation subsystem;

- subsystem of technological preparation of production.

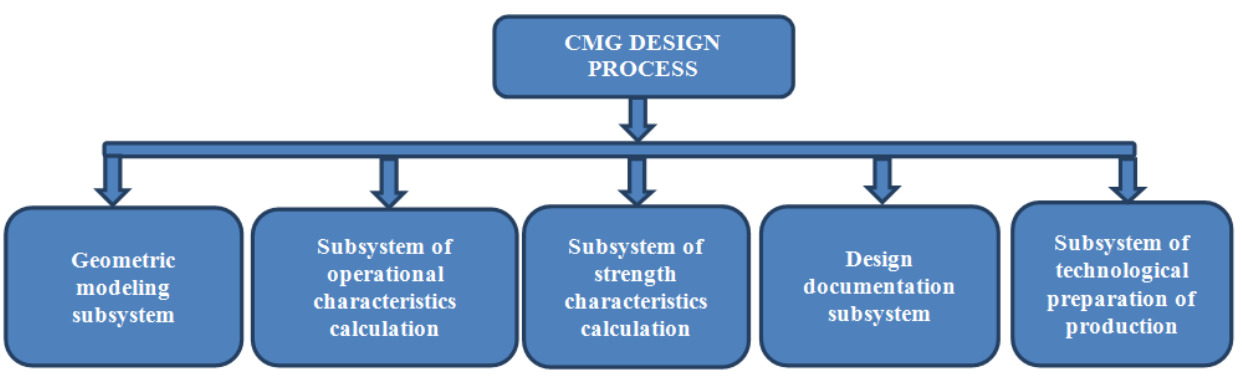

Fig. 1. Block diagram of the CMG design process.

\subsection{Geometrical modeling subsystem}

The geometric modeling subsystem is meant to create the 3D model of CMG. In particular, it is possible to create the 3D models of construction details, assemblies and subassemblies. The Figure 2 presents the main operations which are provided in the geometric modeling subsystem of T-Flex.

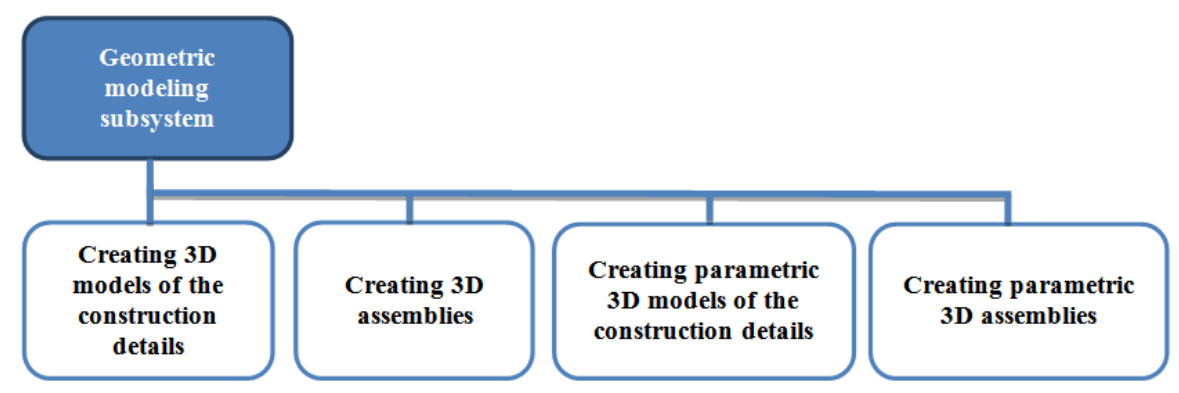

Fig. 2. Block diagram of the CMG designing in geometric modeling subsystem.

\subsection{Subsystem of operational characteristics calculation}

This subsystem is meant to calculate the required operational characteristics and select the optimal construction variant by the specific criteria. The operational characteristics include 
weight-size parameters, critical angular velocity, resisting moment, operational life and others.

T-Flex has the advanced capabilities which allow realizing the operational characteristics calculation depending on the geometry. Using the parametric advantages new operational characteristics can be calculated upon the changing of the geometry. After multiple changes of geometry (search the construction variations) the optimal design will be found according to the required criteria.

The subsystem of operational characteristics calculation is based on the use of the TFlex CAD 2D/3D module. The block diagram of this subsystem is shown in the Figure 3.

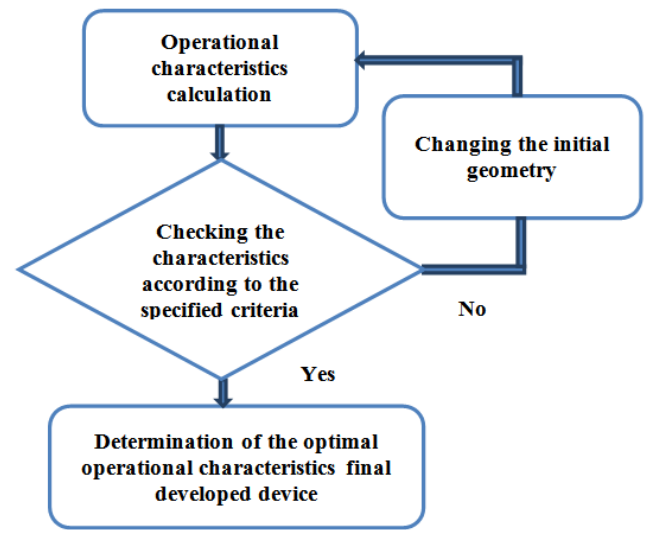

Fig. 3. Block diagram of the subsystem of operational characteristics calculation.

\subsection{Subsystem of strength characteristics calculation}

This subsystem is meant to strength characteristics calculation. The subsystem is based on T-Flex Analysis module.

Module T-Flex Analysis is based on the using of the finite element method (FEM). It allows providing a range of various simulations: mechanical strength, tuned frequencies, stability analysis, thermal analysis and others. This case, the associative relations between geometric 3D model and finite element model are maintained. The grid finite element model will be reorganized after the changes of the initial 3D model. This process is shown in the Figure 4.

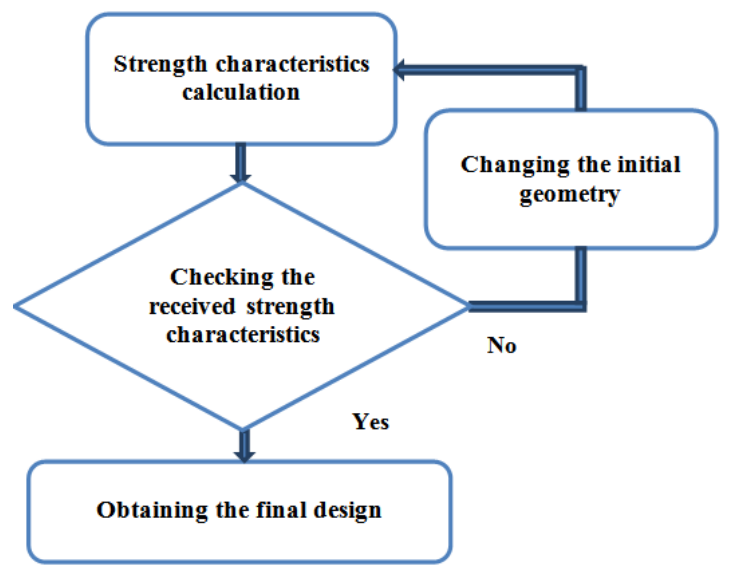

Fig. 4. Block diagram of the subsystem of strength characteristics calculation. 


\subsection{Design documentation subsystem}

The design documentation subsystem is based on the use of the T-Flex CAD 2D/3D module. This module allows creating the design documentation in according to the State Standards requirements. The Figure 5 shows the block diagram of the design documentation subsystem.

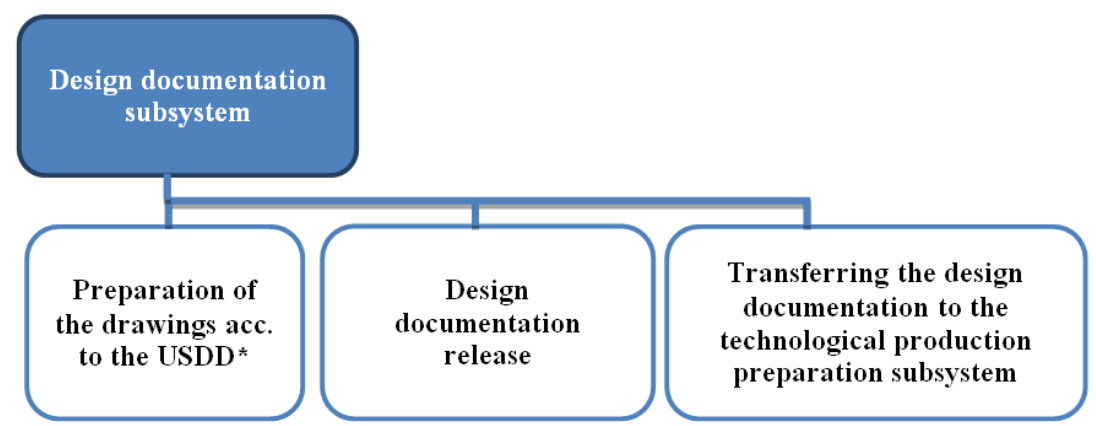

Fig. 5. Block diagram of the design documentation subsystem: * - Unified System for Design Documentation.

At this stage, the design documentation is prepared. Then, drawings and 3D models of the construction details are transferred to the technological preparation of production.

\subsection{Subsystem of technological preparation of production}

The technological production preparation is a set of connected processes which are ensure the technological readiness to produce the products with the required quality, following up to the special terms, quantity and costs. The necessary operations and stages and their content depend on the production type, construction and products application. Under the technological readiness could be understood the availability of a complete set of technological documentation and technological equipment which are necessary for the production [9].

Technological preparation should be carried out in accordance with the requirements of the Unified System of Technological Preparation of Production [10].

The Figure 6 shows the block diagram of the subsystem of technological preparation of production.

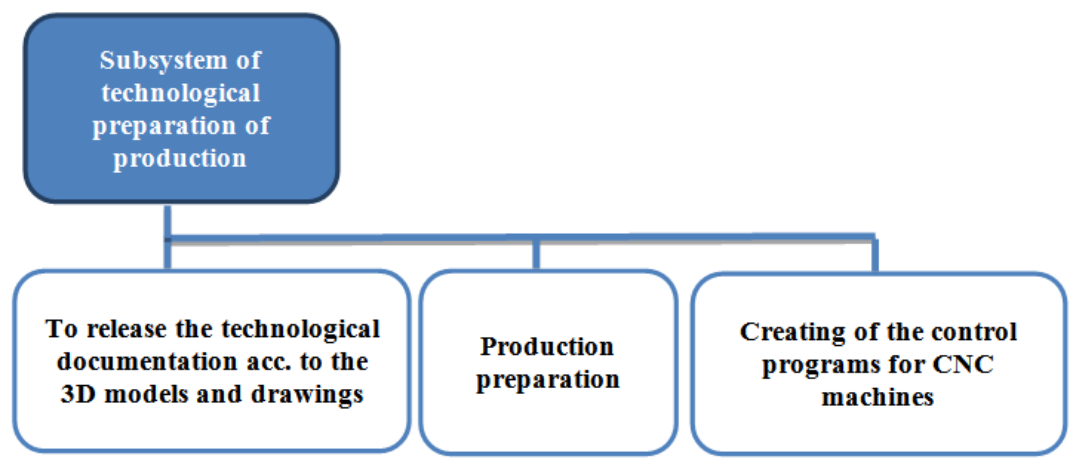

Fig. 6. Block diagram of the subsystem of technological preparation of production. 


\section{Conclusion}

The CAD-system in application of designing the CMG allows developing the complex electromechanical device fast and with the high quality. At the same time, the optimal operational characteristics can be obtained. All these aspects are the basis for the device production.

\section{References}

1. P. Baranov et. al. 14th IMEKO TC10 Workshop on Technical Diagnostics, 90, (2016)

2. K. Lalit Narayan, Computer Aided Design and Manufacturing (EDP Prentice Hall of India, New Delhi, 2008)

3. Michael Phiri, Information Technology in Construction Design ( EDP Thomas Telford Publishing, London, 1999)

4. A. V. Taracenko, V. S. Dmitriev, T. G.Kostuchenko, KORUS, 83, (2005)

5. Yu. Britova, V. Dmitriev, T. Kostyuchenko, IOP Conference Series: Materials Science and Engineering 132(1), (2016)

6. V. Dmitriev, Y. Britova, MATEC Web of Conferences 01005, (2016)

7. V. Ogay, P. Baranov, A. Stepankova, IOP Conference Series: Materials Science and Engineering 66(6), (2014)

8. A. G. Dolgih, V. M. Martemyanov, SIBCON, 7491844 (2016), DOI: 10.1109/SIBCON.2016.7491844

9. D. A. Madsen, Engineering Drawing and Design (EDP Clifton Park, NY, 2012)

10. G. Farin, J. Hoschek, M. Kim, Handbook of computer aided geometric design (EDP Elsevier, 2002) 